\title{
Remarkable Enhancement of Catalytic Activity of Cu- Complexes in the Electrochemical Hydrogen Evolution Reaction (HER) by Using Triply-Fused Porphyrin
}

Shubhadeep Chandra, ${ }^{\dagger}$ Arijit Singha Hazari, ${ }^{\dagger}$ Qian Song, David Hunger, Nicolás. I. Neuman, Joris van Slageren, * Elias Klemm, * and Biprajit Sarkar*

[a] S. Chandra, Dr. A. S. Hazari, Dr. N. I. Neuman, Prof. Dr. B. Sarkar

Lehrstuhl für Anorganische Koordinationschemie, Institut für Anorganische Chemie

Universität Stuttgart

Pfaffenwaldring 55, D-70569, Stuttgart, Germany

E-mail: biprajit.sarkar@iac.uni-stuttgart.de

[b] Dr. Q. Song, E. Klemm

Institute of Chemical Technology

University of Stuttgart

Pfaffenwaldring 55, 70569, Stuttgart, Germany

[c] D. Hunger, J. van Slageren

Institut für Physikalische Chemie

Universität Stuttgart

Pfaffenwaldring 55, 70569 Stuttgart, Germany

[d] Dr. N. I. Neuman

Instituto de Desarrollo Tecnológico para la Industria Química CCT

INTEC, UNL-CONICET, Predio CONICET Santa Fe

Dr. Alberto Cassano, Ruta Nacional $N^{\circ} 168, \mathrm{Km}$ 0, Paraje El Pozo, (S3000ZAA) Santa Fe, Argentina

† S.C and A.S.H contributed equally to this work 


\section{Abstract}

We report here a bimetallic triply fused copper porphyrin complex (1) comprising two monomeric porphyrin units, that exhibits remarkable catalytic activity for the electrochemical HER. For comparison purposes we also present the analogous monomeric copper porphyrin complex (2). Electrochemical investigations in the presence of a proton source confirm that the catalytic activity of the fused metalloporphyrin occurs at a significantly lower overpotential, $(\sim 320 \mathrm{mV})$, compared to the non-fused monomer. Controlled potential electrolysis combined with the kinetic analysis of catalysts 1 and 2 confirm the production of hydrogen, with $96 \%$ and $71 \%$ faradaic efficiencies, with an observed rate constant of $\sim 107$ (s-1) for 1. Additionally, current in the mA region was generated without catalyst decomposition. Our results thus firmly establish the triply fused porphyrin ligands as outstanding candidates for generating highly stable and efficient molecular electrocatalysts in combination with earth-abundant $3 d$ transition metals. 


\section{Introduction}

Rapid depletion of fossil fuels, limited resources, and growing energy demands has led to a global search for alternative energy sources. ${ }^{[1]}$ Hydrogen as an energy carrier is considered as one of the promising alternatives as it is carbon-free and only generates environmentally benign by-product $\mathrm{H}_{2} \mathrm{O}$ upon combustion. ${ }^{[2]}$ Electrocatalytic reduction of protons is one of the reliable strategies for sustainable production of hydrogen. ${ }^{[3]}$ In the recent past, electrocatalytic hydrogen evolution reaction (HER) $\left(2 \mathrm{H}^{+}+\mathrm{e}^{-} \rightarrow \mathrm{H}_{2}\right.$ ), has garnered considerable attention as a new paradigm for energy storage, delivery and transport. ${ }^{[4]}$ To date, elemental platinum is considered as one of the most efficient catalysts for HER; however, low natural abundance and high cost to an extent limit its large-scale applications, prompting researchers to seek alternative non-noble metalbased catalysts. ${ }^{[5]}$ Consequently, substantial effort and time have been devoted towards finding cheap, efficient and robust catalysts comprising of earth-abundant elements. ${ }^{[6]}$ As a result, several earth-abundant transition metals like $\mathrm{Fe},{ }^{[7]} \mathrm{Co},{ }^{[8]} \mathrm{Mo},{ }^{[9]}$ $\mathrm{Cu}^{[10]}$ and $\mathrm{Ni}^{[11]}$ have been recognized as active molecular electrocatalysts for HER

In nature, hydrogenase enzymes containing [Fe-Fe] or [Fe-Ni] active sites catalyse reversible interconversion of protons into hydrogen with low overpotential and high turnover, suggesting the importance of noble metal free bimetallic catalysts. ${ }^{[12]}$ However, difficulties in isolation and utilization of these enzymes under non-natural environments prompted researchers to design different structural and functional models mimicking the active site of hydrogenase. ${ }^{[13]}$ On the other hand, several functional analogues based on bimetallic electrocatalysts inspired by natural enzymes have also been designed and in some cases they were found to exhibit superior catalytic efficiency as compared to their monomeric counterparts. ${ }^{[14]}$ For example, a recent study by Apfel and co-workers demonstrated superior catalytic efficiency of a bimetallic macrocycle featuring two cofacially linked $\mathrm{Ni}(\mathrm{II})$-porphyrin by a linker molecule. ${ }^{[15]}$

In the above context, transition metal complexes of tetrapyrrolic macrocycles such as porphyrins are important due to their unique electrochemical, photophysical properties and the unprecedented reactivity in energy-relevant small molecule activation. ${ }^{[16]}$ Over the years, several $\mathrm{Fe}, \mathrm{Ni}$, Co, Mo and $\mathrm{Cu}$ complexes of porphyrins have gained substantial attention as HER catalysts. ${ }^{[17,18]}$. The advantage of porphyrins over other molecular catalysts lies in the ease with which the substitution pattern at the periphery controls proton transfer ability, substrate accessibility and selectivity in 
product formation. ${ }^{[19,20]}$ For example, hanging carboxylic groups at the backbone of $\mathrm{Ni}(\mathrm{II})$ hangman porphyrins, was shown to facilitate HER mediated by proton coupled electron transfer activity has been demonstrated. ${ }^{[19]}$

Copper, due to their rich redox chemistry and prominent role in various redox processes in biological systems has been shown to exhibit catalytic activity in $\mathrm{CO}_{2}$ reduction or water oxidation reactions. ${ }^{[21]}$ However, the use of Cu-based materials in HER is comparatively rare, with a handful of examples reported from the group of Cao and co-workers and Gross and co-workers. ${ }^{[22]}$ Limited use of $\mathrm{Cu}$-containing complexes for HER are due to the enhanced propensity of Cu-based molecular catalyst to undergo demetallation under reducing conditions, forming Cu-nanoparticles or depositing on electrodes, all of which can catalyze HER in their own right. Therefore, the contemporary challenges in developing molecular electrocatalysts for HER is to develop systems that will operate at low over-potentials with high turnover numbers and remain stable under electrocatalytic conditions, while generating high current densities.

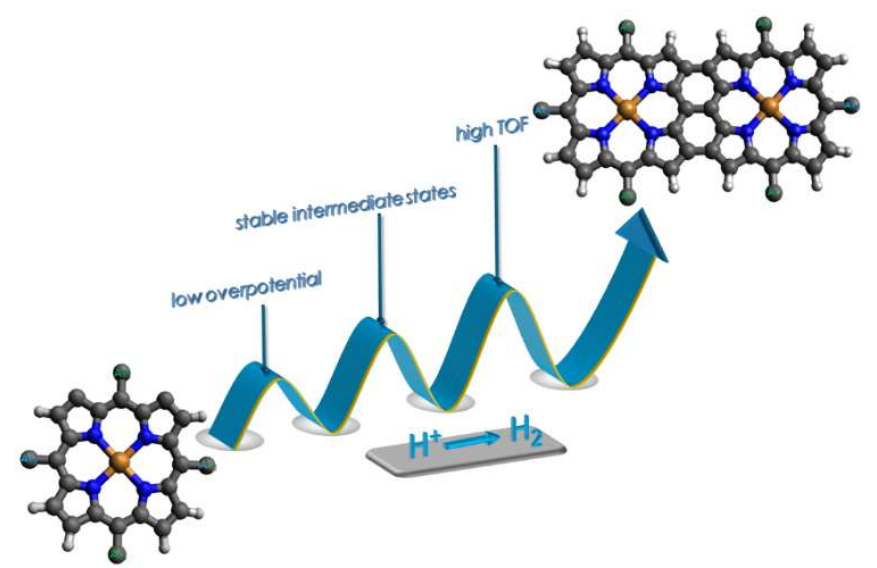

Figure 1. Advantages of fused porphyrin for electrocatalytic studies.

While, metal complexes of monoporphyrin have been exploited extensively for electrocatalytic $\mathrm{HER}, \mathrm{OER}$ and $\mathrm{CO}_{2}$ reduction reactions, similar studies comprising bimetallic fused porphyrins are limited to a single example (see below). Fused porphyrins are unique structural motifs, where two monoporphyrin units are connected via $\beta-\beta$, meso-meso, $\beta^{\prime}-\beta^{\prime}$ triple covalent linkages. ${ }^{[23]}$ Metal complexes of fused porphyrins can be considered as a promising candidate towards electrochemical HER due to their ability to undergo reductions or oxidations at lower applied potentials compared to their monomeric counterparts and extensive delocalization of $\pi$-electrons across the ligand (Figure 1). In this context, Moore and co-workers for the very first 
time illustrated enhanced catalytic efficiency of doubly fused bimetallic copper porphyrins over the analogous nonfused monomeric copper porphyrin, in electrocatalytic HER. ${ }^{24]}$

In the present contribution, we report the first example of HER catalysts based on the triply-fused bimetallic copper porphyrin (1) and draw a comparison of the catalytic activity with analogous monomeric Cu-porphyrin (2) and bimetallic zinc porphyrin (3) (Chart I). Electronic structures of the complexes were probed via a combination of methods including cyclic voltammetry, EPR/UV-Vis-NIR spectroelectrochemistry and DFT calculations. Furthermore, catalytic activity of the fused and monoporphyrin complexes towards electrochemical HER was investigated using TFA as a proton source. Different kinetic and thermodynamic factors governing the catalytic activity of the complexes were extracted from various electrochemical experiments. The primary objective of the work is the development of a molecular catalysts for electrochemical HER that will allow generation of high current densities while operating at low overpotentials and high turnover numbers. To the best of our knowledge, this is the first report on the electrocatalytic activity of a metal complex with a triply fused porphyrin ligand, and the system presented here fullfill all the aforementioned sought after parameters for molecular electrocatalysts.

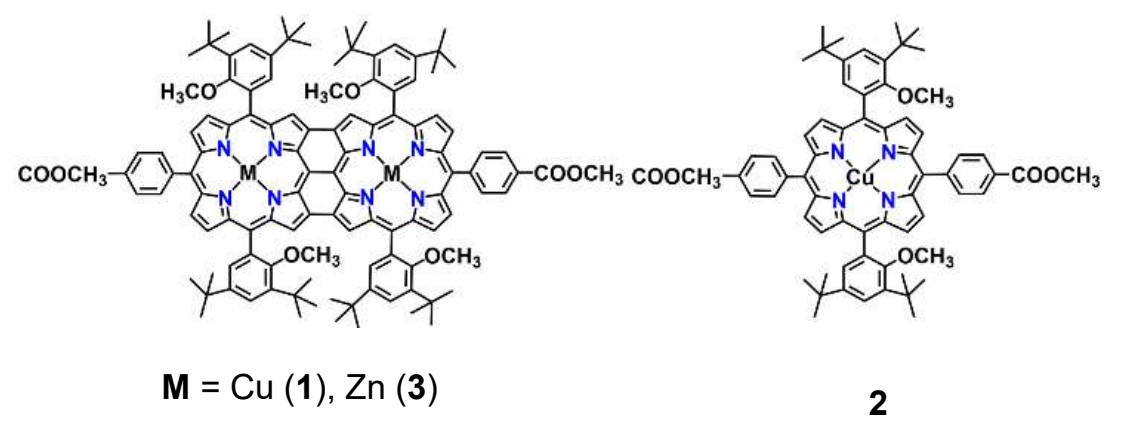

Chart I. Molecular structures or ule complexes studied in this work. 


\section{Results and Discussion}

Dinuclear and mononuclear copper complexes $\mathbf{1}$ and $\mathbf{2}$ were synthesized by insertion of copper into the free-base fused porphyrin and its tetrasubstituted monomeric analogue by the reaction of copper acetate in chloroform/methanol (10:1) solvent mixture, at room temperature (2) and under refluxing condition (1). Purification of the crude material via column chromatography and recrystallization from chloroform/methanol yielded violet-colored pure compoundS in moderate yields. Molecular identity of all the precursor materials (complexes 3, 5, 6, 7) and the fused and monomeric porphyrin complexes ( $\mathbf{1}$ and $\mathbf{2}$ ) has been carried out via a combination of experimental techniques such as ESI-MS, ${ }^{1} \mathrm{H}-\mathrm{NMR}$, UV-Vis-NIR absorption and EPR spectroscopy (Figures S1-S6, Experimental details). The free base triply fused porphyrin exhibited characteristic NMR signals, as reported in the literature, ${ }^{[25]}$ in which peaks are shifted to higher fields due to the effect of $\pi$-electron delocalization on the ring current. Crystals suitable for X-Ray diffraction were obtained via slow diffusion of a benzene solution of the complex into ethanol; however, due to the poor quality of the crystals, reliable bond parameters could not be determined. Nevertheless, the core structure of the ligand along with the coordination mode of the metal is unequivocally established (Figure S7). From the molecular structure, a planar conformation of the fused ligand scaffold is observed, where two copper centers coordinate to four tetrapyrrolic nitrogen atoms of the individual porphyrin units, indicating coplanar arrangements of the copper and ligand framework.

Electrochemical properties of the complexes have been evaluated via cyclic voltammetric (CV) and differential pulse voltammetric (DPV) analysis in $\mathrm{N}, \mathrm{N}$,dimethylformamide solution (DMF) containing $0.1 \mathrm{M}$ tetrabutylammonium hexafluorophosphate $\left({ }^{n} \mathrm{Bu}_{4} \mathrm{PF}_{6}\right)$ as the supporting electrolyte, at $100 \mathrm{mV} / \mathrm{s}$ scan rate. Cyclic voltammograms of the dinuclear complex 1 display multiple redox processes in the potential window spanning from $+1 \rightarrow-3 \vee$ (Figure $S 8$ and Table S1). The cyclic voltammogram of the fused complex 1 , within the potential window ranging from $0 \rightarrow$ $-2 \mathrm{~V}$, reveals three reversible redox features with half wave potentials, $E_{1 / 2}^{\text {red } 1}=-0.86 \mathrm{~V}$, $E_{1 / 2}^{r e d 2}=-1.16 \mathrm{~V}$ and $E_{1 / 2}^{\text {red }}=-2.06 \mathrm{~V}$, against the ferrocene/ferrocenium $\left(\mathrm{FcH} / \mathrm{FcH}^{+}\right)$ redox couple (Figures 2, S8, and Table S1). On the other hand, monomeric complex 2 under identical experimental conditions display two reduction processes at $E_{1 / 2}^{\text {red11}}=$ $-1.66 \mathrm{~V}$ and $E_{1 / 2}^{r e d 2}=-2.12 \mathrm{~V}$ respectively. The peak separation of $\left(\Delta E_{\mathrm{p}}\right) \sim 85 \mathrm{mV}$, 
between the cathodic and anodic waves of all redox processes in both the complexes, implies one electron redox processes (considering $\Delta E_{\mathrm{p}}=80 \mathrm{mV}$ for the $\mathrm{Fc} / \mathrm{Fc}^{+}$redox couple). Notably, the first and second reduction process in complex 2 were cathodically shifted by 802 and $302 \mathrm{mV}$, respectively, compared to the dinuclear complex 1 .

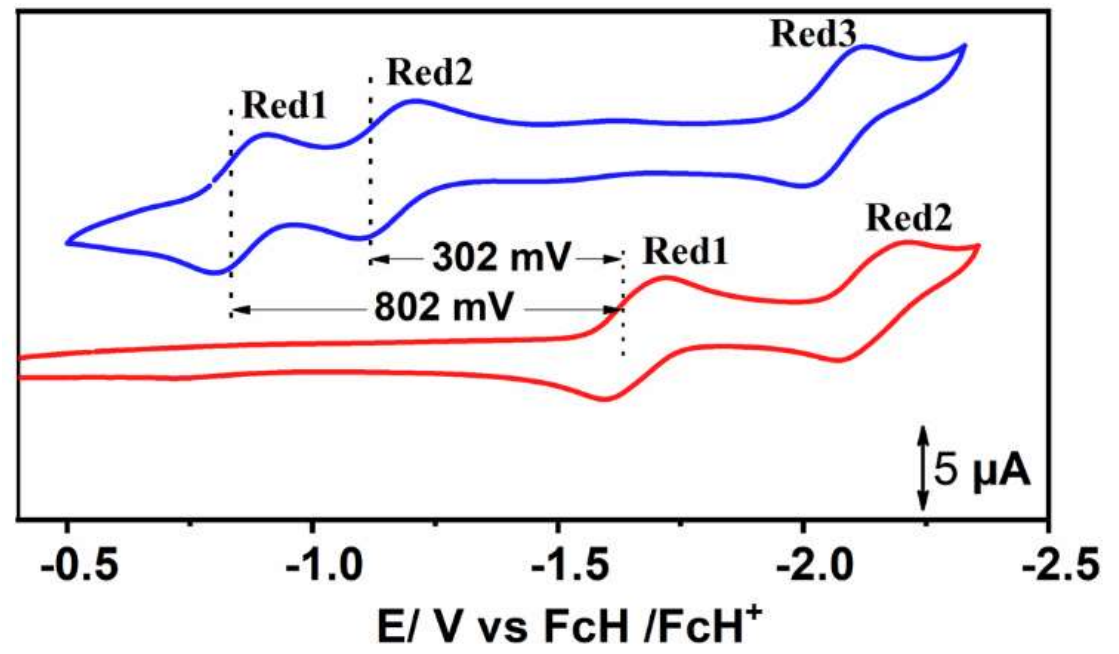

Figure 2. Cyclic voltammograms of triply-fused metalloporphyrin 1 (blue) and monomeric analogue 2 (red) in DMF.

This difference in peak potentials between triply-fused dinuclear metalloporphyrin (1) and the monomeric analogue (2) in the present investigation, is more pronounced than the previously reported Cu-complexes of doubly fused and monomeric metalloporphyrins, ${ }^{[24]}$ which is consistent with our motivation for preparing these complexes. Considerable differences in the redox potentials in this case can be rationalized from the extensive delocalization of $\pi$-electrons across the covalently linked porphyrin units. The corresponding $\mathrm{Zn}$ (II)-fused porphyrin displayed identical behaviour under similar experimental conditions The shift in potential is consistent with the subsequent increase in electrochemical HOMO-LUMO gap from 1 to $2(1.10 \mathrm{eV}$ and $3.20 \mathrm{eV}$ ). Electrochemical data of the complexes are summarized in Table S1. Thus, the bimetallic fused porphyrin, with significantly shifted redox potentials in comparison to the monomeric complex encouraged further investigation of these complexes towards electrochemical HER.

EPR spectroscopy in combination with variable temperature magnetic susceptibility $(\chi \mathrm{T})$ were performed to investigate the nature of the magnetic interactions between copper centers in complexes 1 and $\mathbf{2}$ (Figure 3). The room temperature $\chi^{\top}$ value of $0.85 \mathrm{~cm}^{3} \mathrm{~mol}^{-1} \mathrm{~K}$ for 1 corresponds to that expected for two uncoupled spin doublets with $g=2.13$ (Figure 3). On cooling, the $\chi \top$ value remains essentially constant down 
to until $40 \mathrm{~K}$, following which a sharp drop in the value was observed reaching a $\chi^{\top}$ value of $0.15 \mathrm{~cm}^{3} \mathrm{~mol}^{-1} \mathrm{~K}$ at the lowest temperatures.

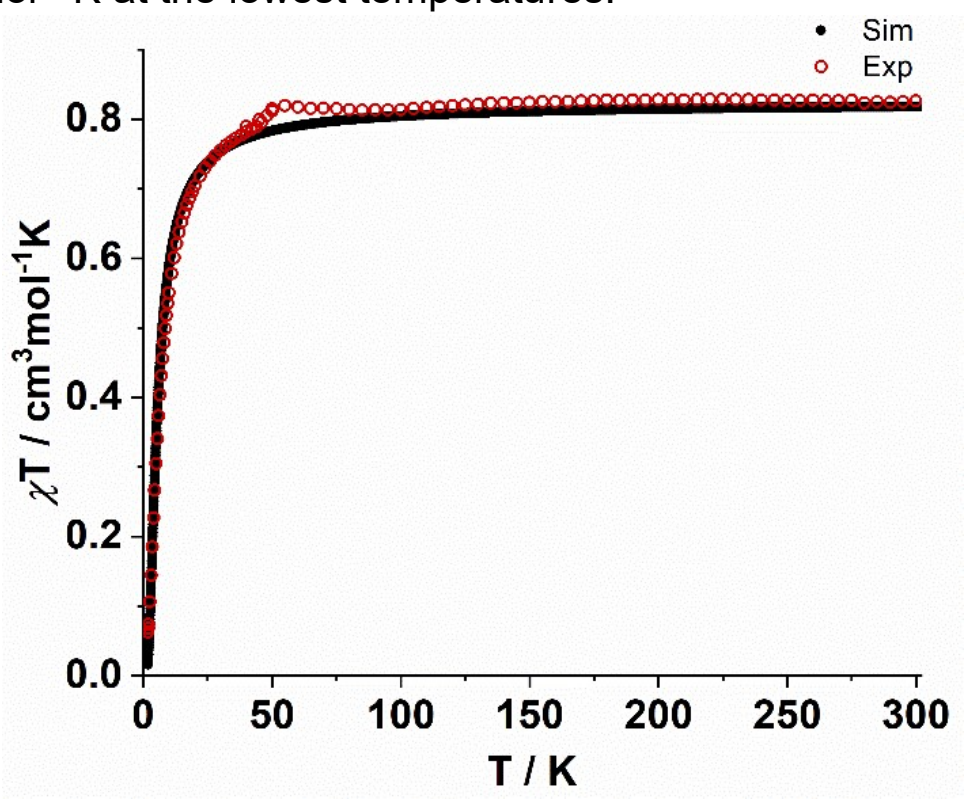

Figure 3. Magnetic susceptibility temperature product as a function of temperature, recorded on a powder sample of 1 in the temperature range $1.8-300 \mathrm{~K}$.

The exchange coupling constant of $J=-6.69 \mathrm{~cm}^{-1}$, obtained via least-squares fitting of the Bleaney-Bowers equation ${ }^{[26]}$ using spin-hamiltonian $\hat{H}=-2 J \hat{S}_{1} \hat{S}_{2}$, agrees well with the literature reported data. ${ }^{[27]}$ Furthermore, the value of the magnetic susceptibility $(\chi \mathrm{T})$ was found to be consistent with the EPR derived parameters ( $g$-values, see below).

The EPR spectrum of pure solid 1 at $98 \mathrm{~K}$ reveals a broad resonance line containing a multiline pattern due to hyperfine coupling of the electron spin $(S=1)$ to both ${ }^{63,65} \mathrm{Cu}$ nuclei $(I=3 / 2)$, consistent with the previously reports (Figures $4, \mathrm{~S} 10$ and Table S2). ${ }^{[28]}$ The best fit to the experimental EPR data was obtained by fitting the spectra obtained from a spin-Hamiltonian consisting of an $\mathrm{S}=1$ spin coupled to two equivalent ${ }^{63,65} \mathrm{Cu}(\mathrm{II})$ nuclei $(I=3 / 2)$. The good agreement between the simulated and experimental spectra allowed determination of the rhombic g-matrix, with $g$-values $\left(g_{\mathrm{x}}, g_{\mathrm{y}}, g_{\mathrm{z}}\right)$ of 2.06, 2.00, 2.22. The $g_{z}$ region shows a partially resolved hyperfine pattern consisting of seven lines with a 1:2:3:4:3:2:1 intensity pattern (with the first five lines clearly resolved), typical of hyperfine interaction with two equivalent ${ }^{63,65} \mathrm{Cu}(\mathrm{II})$ nuclei $(I=3 / 2)$. The associated $\mathrm{A}_{z}$-value $=308 \mathrm{MHz}$ is roughly half of the one observed for the monomer, which is indicative of an exchange coupled $S=1$ state $\left(A_{S=1}=(1 / 2) A_{S=1 / 2}\right)$. ${ }^{29]}$ The absence of half-field transitions $(\Delta \mathrm{Ms}= \pm 2)$ even at lower temperature implies weak zero-field splitting interaction, despite the triplet state spin structure, which has also 
been reported in the literature for diporphyrins with large center to center distances. ${ }^{[30]}$ Thus, rhombic distortion of the $g$-values and lower $A_{z}$-value in case of 1 indicate sharing of two unpaired electrons between two porphyrin units. Therefore, the multiline spectrum of 1 arises mainly because of the thermally populated triplet state $(S=1)$ over the singlet state $(S=0)$.

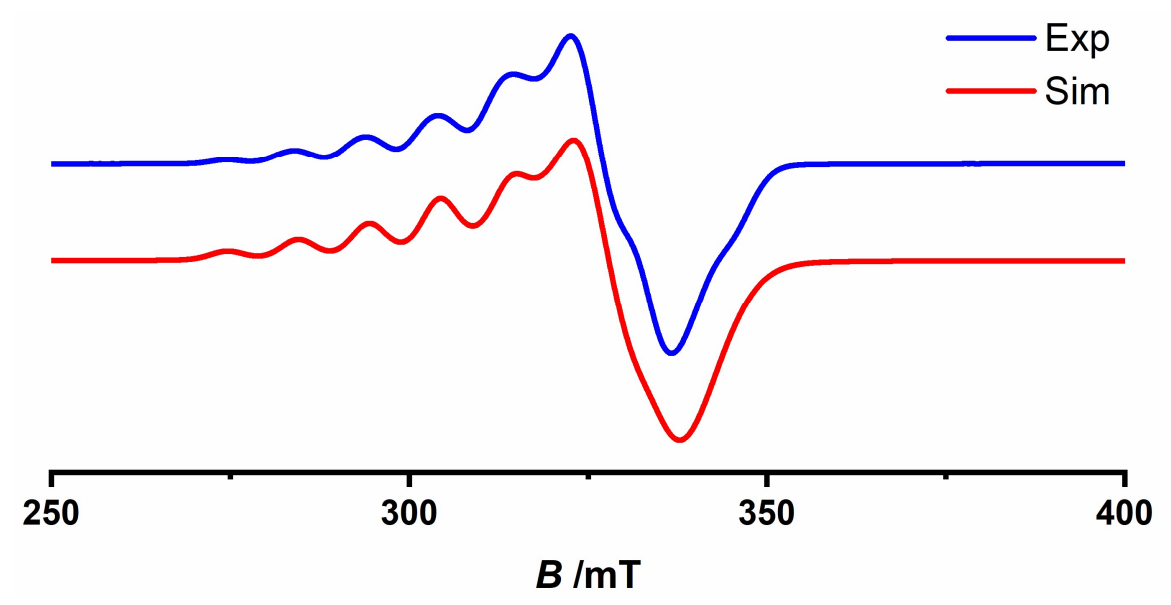

Figure 4. Experimental (blue) and simulated (red) EPR spectra of the complex 1 at $98 \mathrm{~K}$.

EPR spectra of mononuclear copper porphyrin (2) measured at $98 \mathrm{~K}$ display a multiline pattern arising from the hyperfine interaction to a single ${ }^{63,65} \mathrm{Cu}(I=3 / 2)$ and four ${ }^{14} \mathrm{~N}(\mathrm{I}=1)$ nuclei (Figure S11 and Table S2). The experimental spectrum has been reasonably fitted with by a simulation of an $S=1 / 2$ spin Hamiltonian with hyperfine interaction to the previously described nuclei with an axial g-matrix. The values of $g_{\|}=$ $2.19\left(A_{\|}=596 \mathrm{MHz}\right)$ and $g_{\perp}=2.045(\mathrm{~A}$ perp $=62 \mathrm{MHz})$, agrees well with the reported literature data for related Cu-monoporphyrin complexes. ${ }^{[31]}$

Thus, small but non-negligible exchange coupling constant, as well as the sevenline hyperfine pattern in the EPR spectrum of 1 underlines the important role of the conjugation between individual porphyrin units in the long-range antiferromagnetic coupling.

Successive changes in the electronic and vibrational structure of the complexes 1 and 2 upon consecutive reductions have been evaluated via UV-Vis-NIR spectroelectrochemical studies. UV-Vis-NIR absorption profiles of complexes $\mathbf{1}$ and $\mathbf{2}$ in DMF reveal significant differences with three distinct absorption bands in $\mathbf{1}$, in contrary to two bands in 2 (Figures 5, S13, S14 and Table S3). ${ }^{[25]}$

Monomeric complex 2 exhibited absorption bands at 417 and $536 \mathrm{~nm}$ respectively corresponding to Soret and Q-band transitions. In contrast, the Soret-like transitions in 
complex 1 are splitted into two bands at $414 \mathrm{~nm}$ and $576 \mathrm{~nm}$ (band I and II, respectively), owing to the excitonic coupling between the individual porphyrin units. On the other hand, the Q-band like features in 1 are significantly red shifted at 887 and $986 \mathrm{~nm}$ compared to the Q-bands of 2 , attributed to the extensive conjugation between the diporphyrin $\pi$-electron systems.

In the case of complex 1, upon reduction, the Soret bands at 414 and $576 \mathrm{~nm}$ underwent bathochromic shifts to 415 and $611 \mathrm{~nm}$ with distinct isobestic points, inferring stable conversion without an involvement of transient species or decomposition products. On the other hand, the Q-band transitions display hypsochromic shifts to $865 \mathrm{~nm}$ along with an appearance of a new band at $1293 \mathrm{~nm}$ possibly due to the intra-ligand charge transfer transitions. The monomeric complex 2 upon reduction exhibits similar behavior, with an appearance of a band at $877 \mathrm{~nm}$ in addition to the Q-band transition at $666 \mathrm{~nm}$. Further reduction of the monoanionic species leading to dianionic species $1^{2-}$, resulted in the growth of a low energy NIR band at $\sim 1600 \mathrm{~nm}$ with concomitant reduction in intensity of the existing absorption bands. Notably, application of starting potential of $0 \mathrm{~V}$ to the in-situ generated species resulted in the recovery of the UV-Vis spectrum identical to the native species, underlining the reversibility of the redox processes. Spectroelectrochemical response of 1 upon $1 \mathrm{e}^{-}$oxidation resulted in the decrease in intensity of the Soret bands and blue shift of the Q-bands to 688 and $723 \mathrm{~nm}$, in addition to formation of new low-energy band at $1572 \mathrm{~nm}$, with clearly defined isobestic points, implying formation of porphyrin $\pi$-cation radical $1^{+}$. Successive oxidation of the intermediate monocationic species $\mathbf{1}^{+}$ to the respective dication resulted in further decrease in intensity of the existing absorption bands.
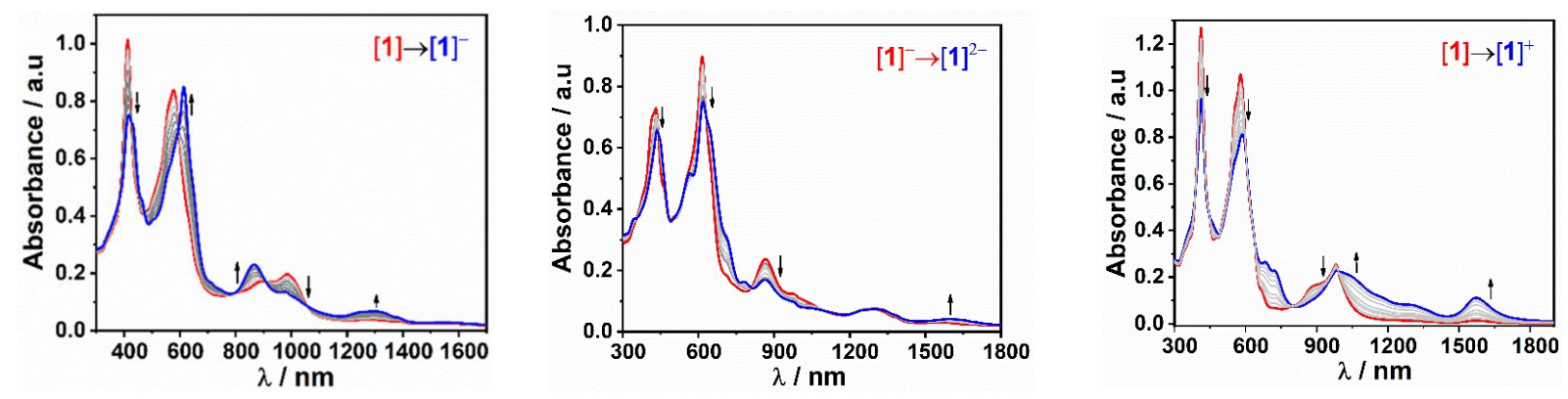

Figure 5. UV-Vis-NIR spectroelectrochemical responses of $1^{\mathrm{n}}$ in $\mathrm{DMF} / 0.1 \mathrm{M}^{\mathrm{n}} \mathrm{Bu}_{4} \mathrm{PF} 6$ solution. 
Catalytic activity of the fused and monoporphyrin complexes 1 and 2 towards

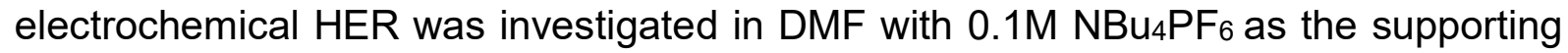
electrolyte under $\mathrm{Ar}$ in the presence of trifluoroacetic acid (TFA, pKa $=6.1$ in DMF) (Figure 6a). All the measurements were performed in a three electrode configuration electrochemical cell equipped with glassy carbon working electrode, platinum wire as a counter electrode and Ag-wire as a pseudoreference with ferrocene/ferrocinium $\left(\mathrm{FcH} / \mathrm{FcH}^{+}\right)$redox couple as an internal reference. Significantly, upon addition of varying concentrations of TFA to a $0.01 \mathrm{mM}$ solutions of the complexes, a large electrocatalytic current associated with an irreversible cathodic wave appeared at an onset potential of $-0.96 \mathrm{~V}$, which reached maximum at $-1.94 \mathrm{~V}$, with a half wave potential of $-1.42 \mathrm{~V}$ for 1 (Figures $6 \mathrm{a}$ and S15). Notably, appearance of catalytic reduction waves near to the $\mathbf{1}^{2-} / \mathbf{1}^{-}$(second reduction) redox process indicated

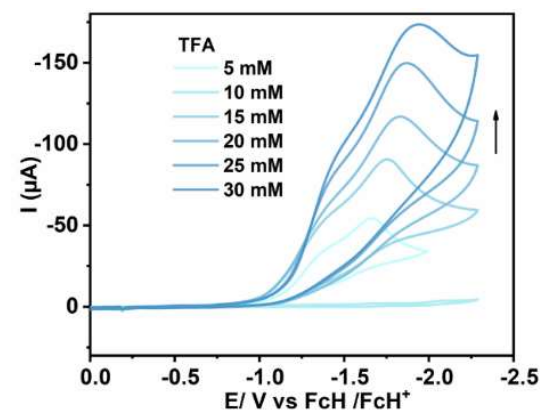

(a)

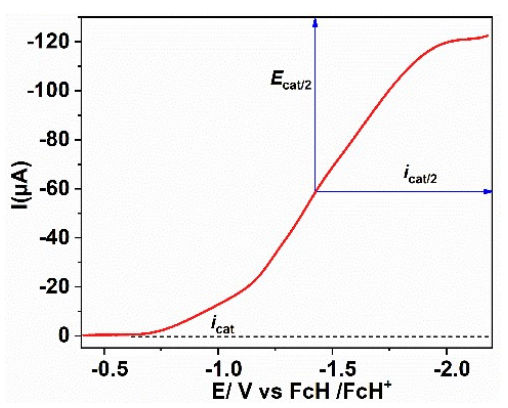

(b)

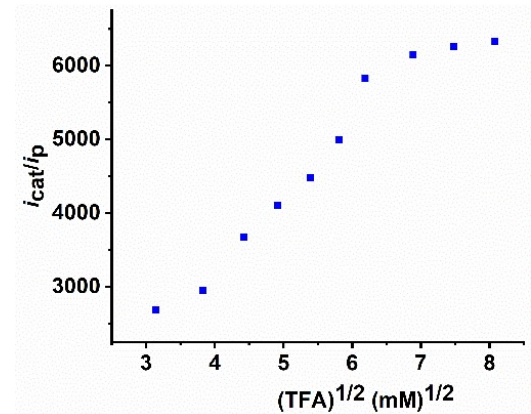

(c)

Figure 6. a) Cyclic voltammetric responses of $0.01 \mathrm{mM}$ DMF solution of 1 with increasing concentration of TFA (Condition: $100 \mathrm{mV} / \mathrm{s}$ scan rate, under $\mathrm{Ar}, 0.1 \mathrm{M}$ $\left.{ }^{n} \mathrm{Bu}_{4} \mathrm{PF}_{6}\right)$. b) Cyclic voltammogram of $0.01 \mathrm{mM}$ DMF solution of 1 containing $15 \mathrm{mM}$ of TFA and $0.1 \mathrm{M}$ of electrolyte at $300 \mathrm{mV} / \mathrm{s}$ scan rate, showing a close to ideal S-shape. c) Plot of $\mathrm{i}_{\text {cat }} / \mathrm{i}_{\mathrm{p}}$ versus square root of the scan rate.

possible involvement of doubly reduced species in HER. This is corroborated by the lack of significant changes in the reversible nature of the first reduction wave before and after addition of TFA. From the thermodynamic potential required for the reduction of TFA in DMF ( -0.94 V), the overpotential for HER for 1 , was calculated to be $\sim 480$ $\mathrm{mV}$ (Figure 6b).

Consistent with the analogy proposed by Saveant and co-workers, an ideal $S$ shaped curve was obtained at higher scan rate of $300 \mathrm{mV} / \mathrm{s}$ and $15 \mathrm{mM}$ of acid concentration (Figure 6b). The ideal nature of the voltammogram at relatively higher scan rate and acid concentrations refer to the typical condition where concentration of 
the substrate at the electrode surface is equal to the concentrations of the bulk solutions i.e. pure kinetic conditions with no substrate depletion. Under this condition, the fraction of the activated catalyst at the electrode surface is unity, therefore observed rate constant ( $k_{\text {obs }}$ ), which is equivalent to TOF $\max$. can be calculated from the plateau current of the S-shaped curve. ${ }^{[32]}$ The linear dependence of peak current $\left(i_{p}\right)$ with the square root of the scan rate $\left(v^{1 / 2}\right)$ confirmed catalysis in the diffusioncontrolled electrochemical regime under these experimental conditions (Figure S16). The catalytic current $\left(i_{\text {cat }}\right)$ associated with the S-shaped catalytic wave increased linearly with scan rate following a first-order rate dependence. Importantly, the linear dependence of $i_{\text {cat }}$ Over scan rate $(v)$ no longer holds when scan rate exceeds $0.5 \mathrm{~V} / \mathrm{s}$ indicating proximity to the saturation point (Figure S17). Furthermore, plateau currents at a fixed scan rate of $300 \mathrm{mV} / \mathrm{s}$ was found to be directly proportional to $v^{1 / 2}$ following a first-order rate constant. However, increasing TFA concentrations beyond $40 \mathrm{mM}$ led to the saturation point, beyond which addition of further acid has almost no effect on the catalytic current (Figure 6c) indicating zeroth-order rate dependence on acid. Notably, under identical experimental conditions $(0.01 \mathrm{mM}$ of caatlyst and $15 \mathrm{mM}$ of acid), 2 displayed irreversible catalytic wave with a significant cathodic shift ( $600 \mathrm{mV}$ ) in the onset potential as compared to 1, underlining higher activity of the $\mathbf{2}$ over $\mathbf{1}$ (Figure 7). Moreover, comparison of the catalytic efficiency under identical experimental conditions $(0.01 \mathrm{mM}$ and $15 \mathrm{mM}$ of catalyst and acid) revealed considerably higher overpotential $(\sim 800 \mathrm{mV})$ in the case of 2 as compared to 1 for HER. Thus, catalyst 1 lowers the overpotential by $\sim 320 \mathrm{mV}$ compared to 2 for catalytic proton reduction, indicating enhanced activity of bimetallic complex.

Since 1 possesses two individual porphyrin units linked together, evaluation of the electrochemical HER activity was also performed using twice as much concentration

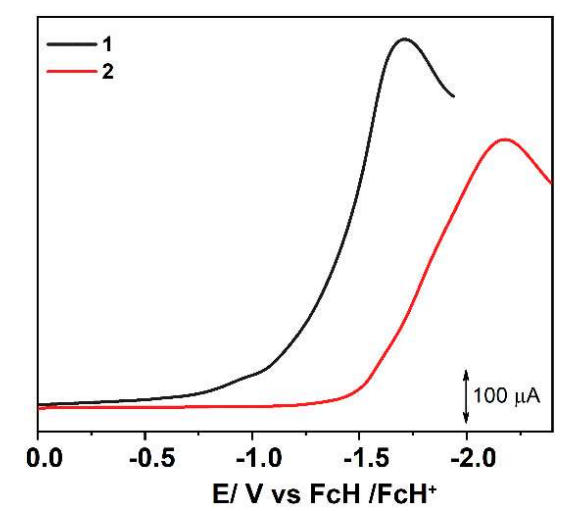

Figure 7. Linear sweep voltammograms of $0.01 \mathrm{mM}$ DMF solutions of 1 (black) and 2

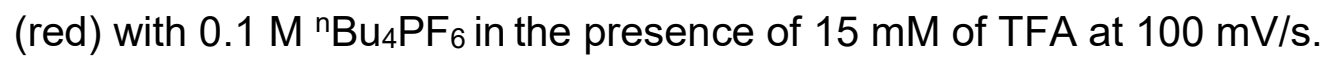


(0.02 mM) of 2 against $0.01 \mathrm{mM}$ of 1 with a fixed acid concentration (15 mM) (Figure S18). Linear sweep voltammograms of 0.01 and $0.02 \mathrm{mM}$ solutions of 1 and $\mathbf{2}$, respectively, under otherwise identical experimental conditions, revealed that even at higher concentration complex 2 exhibit catalytic activity at potentials $\sim 300 \mathrm{mV}$ negative (higher overpotentials) to that of the lower concentration solution of complex 1 (Figure S18). It clearly suggests better catalytic efficiency of $\mathbf{1}$ over 2 towards HER. Importantly, addition of $15 \mathrm{mM}$ of TFA to a DMF solution containing $0.1 \mathrm{M}^{n} \mathrm{Bu}_{4} \mathrm{PF}_{6}$ in the absence of catalyst showed no catalytic currents under otherwise similar experimental conditions (scan rate: $100 \mathrm{mV} / \mathrm{s}$ ) (Figure S19). On the other hand, electrochemical measurements containing $0.01 \mathrm{mM}$ solution of the corresponding $\mathrm{Zn}$ complex 3 in presence of TFA (15 mM) under identical experimental conditions $(0.1 \mathrm{M}$ ${ }^{n} \mathrm{Bu}_{4} \mathrm{PF}_{6}$, scan rate: $100 \mathrm{mV} / \mathrm{s}$ ) displayed a $\sim 400 \mathrm{mV}$ cathodic shift in onset potential compared to 1 , highlighting influence of the metal $(\mathrm{Zn}$ vs. $\mathrm{Cu})$ on the catalytic activity (Figure S19).

Different control experiments were performed to rule out possible detrimental sideeffects of various components in the catalytic processes. Initially, to eliminate the effect of catalyst deposition on the electrode surface during electrocatalytic process, the glassy carbon electrode used in HER was taken out of the solution after catalysis and rinsed properly to get rid of the adsorbed species and dipped into a solution of DMF containing only $15 \mathrm{mM}$ of TFA and $0.1 \mathrm{M}$ of $n \mathrm{Bu}_{4} \mathrm{NPF}_{6}$ in the absence of a catalyst. Absence of any catalytic current above the background obtained from the rinse test rules out any role of electrode adsorbed active catalysts in HER (Figure S20). Control experiment using $\mathrm{Hg}$-pool working electrode were conducted to detect involvement of metal nanoparticles in proton reduction, since some metal particles are inactivated in the presence of $\mathrm{Hg}(0)$ due to adsorption or amalgamation resulting in loss of catalytic acitvity. However, no such differences in catalytic current in the presence or absence of the $\mathrm{Hg}$-pool electrode eliminate any influence of metal nanoparticles in catalytic activity, underlining the role of molecular catalysts in HER (Figure S21). ${ }^{[33]}$ The influence of leached platinum particles that could detach from the platinum counter to HER could also be rejected based on no difference in catalytic activity when using a glassy working electrode instead of platinum. (Figure S22). ${ }^{[34]}$ Acid-stability of compound 1 was verified from the UV-Vis-NIR spectroscopic measurements of 1 in a 1:1 mixture of TFA/DMF (1:1) solution. The absorption spectra of the acidic solution of 1 did not show any noticeable change even after prolonged periods of $24 \mathrm{~h}$ in the dark 
(Figure S23). ESI-MS analysis of the solution confirm that the tetrapyrrolic core of 1 remains intact and demetallation does not occur.

After establishing the catalytic activity of 1 in electrochemical HER, we calculated the catalytic rate constant (kobs), also referred to as turnover frequency, to compare the efficiency of the catalysts with other reported molecular catalysts. The observed rate constant $\left(k_{\mathrm{obs}}\right)$ was calculated from the ratio of catalytic current ( $\left.i_{\text {cat }}\right)$ and peak current (ip) following equation S3 (Figures 6c, S24 and Table S4) at different acid concentrations and a constant scan rate of $300 \mathrm{mV} / \mathrm{s}^{[32,35]}$ A plot of $k_{\text {obs }}$ against TFA concentrations disclosed first order dependence of rate constant on the concentration of TFA (Equation S3 and Figure S24), when $i_{\text {cat }}$ is independent of scan rate (Equation S1) and directly proportional to square root of TFA. At acid concentration beyond 40 $\mathrm{mM}$, when increasing the concentration of acid has no effect on the plateau current ( $\left.i_{\text {cat }}\right)$, kobs become zeroth order with respect to TFA concentration (Equation S4). The rate constant calculated under this condition carries a value of $1.9 \times 10^{7}$ which is almost two-fold higher in magnitude that previously reported doubly fused copper porphyrin

Table 1. Summary of selected homogeneous $3 d$ molecular electrocatalysts for proton reduction.

\begin{tabular}{|c|c|c|c|c|c|c|}
\hline Complex & $\begin{array}{l}\text { conditions (solvent } \\
\text { and proton source) }\end{array}$ & $\begin{array}{r}\text { Kobs } \\
\left(\mathrm{s}^{-1)}\right. \\
\end{array}$ & $\eta_{(m V)}$ & F.E. ( \%) & $\begin{array}{l}\text { current } \\
\text { range }\end{array}$ & ref. \\
\hline$\left[\mathrm{Ni}\left(\mathrm{P}^{\mathrm{Ph}}{ }_{2} \mathrm{~N}^{\mathrm{Ph}}\right)_{2}\right]\left(\mathrm{BF}_{4}\right)_{2}$ & $\begin{array}{l}{[(\mathrm{DMF}) \mathrm{H}]^{+} \mathrm{OTf}^{-} / 1.2 \mathrm{M}} \\
\mathrm{H}_{2} \mathrm{O}\end{array}$ & $10^{6}$ & 625 & 99 & $\mu \mathrm{A}$ & {$[4]$} \\
\hline$\left[\mathrm{Ni}\left(\mathrm{P}^{\mathrm{Ph}}{ }_{2} \mathrm{~N}_{6} \mathrm{C}_{4} \mathrm{X}_{2}\right)_{2}\right]\left(\mathrm{BF}_{4}\right)_{2}$ & $\begin{array}{l}{[(\mathrm{DMF}) \mathrm{H}]^{+} \mathrm{OTf}^{-} / 1.2 \mathrm{M}} \\
\mathrm{H}_{2} \mathrm{O}\end{array}$ & 1850 & 370 & - & $\mu \mathrm{A}$ & \begin{tabular}{|l|l} 
[3] \\
\end{tabular} \\
\hline$\left[\mathrm{Co}(\mathrm{DO})(\mathrm{DOH}) \mathrm{pnBr}_{2}\right]$ & $\begin{array}{l}\mathrm{CH}_{3} \mathrm{CN} / p \text { - } \\
\text { cyanoanilinium } \\
\text { tetrafluoroborate }\end{array}$ & - & 230 & 99 & $\mu \mathrm{A}$ & \begin{tabular}{|l|l|} 
37] \\
\end{tabular} \\
\hline FeTPP-Cl & $\mathrm{DMF} / \mathrm{Et}_{3} \mathrm{NHCl}$ & $4 \times 10^{5}$ & - & 95 & $\mu \mathrm{A}$ & {$[18]$} \\
\hline Co-hangman porphyrin & $\mathrm{CH}_{3} \mathrm{CN} /$ benzoic acid & - & 920 & 80 & $\mu \mathrm{A}$ & [38] \\
\hline $\mathrm{Cu}_{2} \mathrm{FP}$ & $\mathrm{CH}_{2} \mathrm{Cl}_{2} / \mathrm{TFA}$ & $2 \times 10^{6}$ & - & - & $\mu \mathrm{A}$ & [24] \\
\hline Ni-C ${ }_{6} F_{5}$ Porphyrin & $\mathrm{CH}_{2} \mathrm{Cl}_{2} / \mathrm{AcOH}$ & - & 240 & 96 & $\mu \mathrm{A}$ & [39] \\
\hline$[\text { Ni-porphyrin-L }]_{2}$ & $\mathrm{CH}_{2} \mathrm{Cl}_{2} / \mathrm{AcOH}$ & - & - & 95 & $\mu \mathrm{A}$ & {$[15]$} \\
\hline$[\mathrm{Cp} * \mathrm{Co}-\mathrm{MIC}(\mathrm{Cl})] \mathrm{PF}_{6}$ & $\mathrm{CH}_{3} \mathrm{CN} / \mathrm{AcOH}$ & $4 \times 10^{2}$ & 130 & $80( \pm 20)$ & $\mu \mathrm{A}$ & [40] \\
\hline 1 & DMF/TFA & $\begin{array}{l}0.5 \times \\
10^{7}\end{array}$ & 480 & 97 & $\mathrm{~mA}$ & this work \\
\hline
\end{tabular}

complex. ${ }^{[24]}$ Although direct comparison among HER catalysts is difficult given the complexity and diversity associated with various experimental conditions, the reported rate constant for 1 is remarkably high, and to the best of our knowledge is among the highest reported for first row transition metal complexes in the literature (Table 1).

To quantify the amount of hydrogen evolved, controlled potential electrolysis of 1 and $\mathbf{2}$ was carried out in a gas-tight $\mathrm{H}$-type cell separated by a microporous membrane. 
Linear Sweep Voltammetric (LSV) experiments, carried out with 0.06 and $0.12 \mathrm{mM}$ DMF solutions of $\mathbf{1}$ and $\mathbf{2}$, revealed better efficiency of the catalyst $\mathbf{1}$ in comparison to 2, as shown by the lower onset potential and nearly 4-fold increase in the current density of the former compared to the latter (Figure 8). Bulk electrolysis measurements were performed with $0.06 \mathrm{mM}$ and $0.12 \mathrm{mM}$ solutions of 1 and 2, respectively, in 30 $\mathrm{mL}$ DMF solution containing $0.1 \mathrm{M} \mathrm{TFA}$, at $-1.05 \mathrm{~V}$, under $\mathrm{N}_{2}$ atmosphere. During the electrolysis process, constant cathode potential was maintained and the amount of $\mathrm{H}_{2}$ formed was detected via gas chromatographic analysis (Figure S25). Faradaic efficiency of $\mathbf{1}$ and $\mathbf{2}$ upon controlled potential electrolysis conducted for $\mathbf{3 0}$ minutes, was calculated to be $96.6 \%$ and $71.2 \%$ respectively, underlining enhanced catalytic

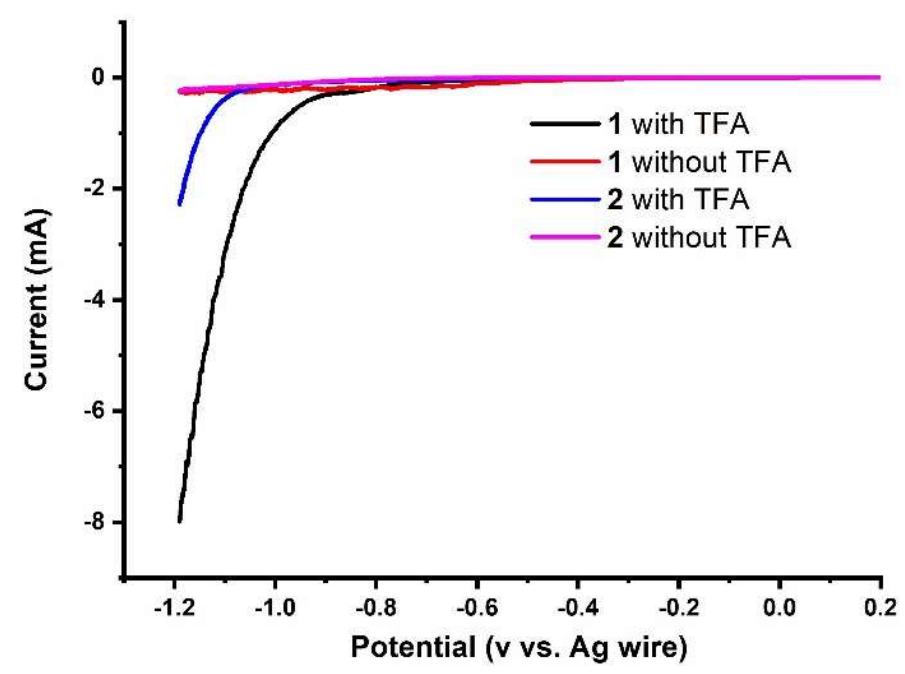

Figure 8. Linear Sweep Voltammograms of $0.06 \mathrm{mM}$ and $0.12 \mathrm{mM}$ DMF solutions of 1 and 2.

performance of 1 compared to 2 towards electrochemical HER (Figure 9). Turnover numbers for 1 and 2 was calculated to be 102 and 18.4 (Figure 9), which indeed supported increased catalytic activity/stability of $\mathbf{1}$ against $\mathbf{2}$. After each electrolysis measurement, the carbon paper working electrode was removed from the electrolyte, rinsed three times with DMF, and reinstalled to perform blind experiments. Linear sweep voltammograms were recorded with fresh solutions of DMF containing $0.1 \mathrm{M}$ $\mathrm{nBu}_{4} \mathrm{PF}_{6}$ and $0.1 \mathrm{M}$ TFA, without any catalysts. Lack of any substantial background current ruled out any involvement of adsorbed catalytic species such as $\mathrm{Cu}$ nanoparticles deposited onto the electrode surface during the electrocatalytic process (Figures S26 and S27). UV-Vis-NIR spectra of the catalysts before and after electrolysis exhibited no significant changes (Figure S28), confirming the stability of the catalysts during electrocatalytic $\mathrm{H}_{2}$ evolution. 


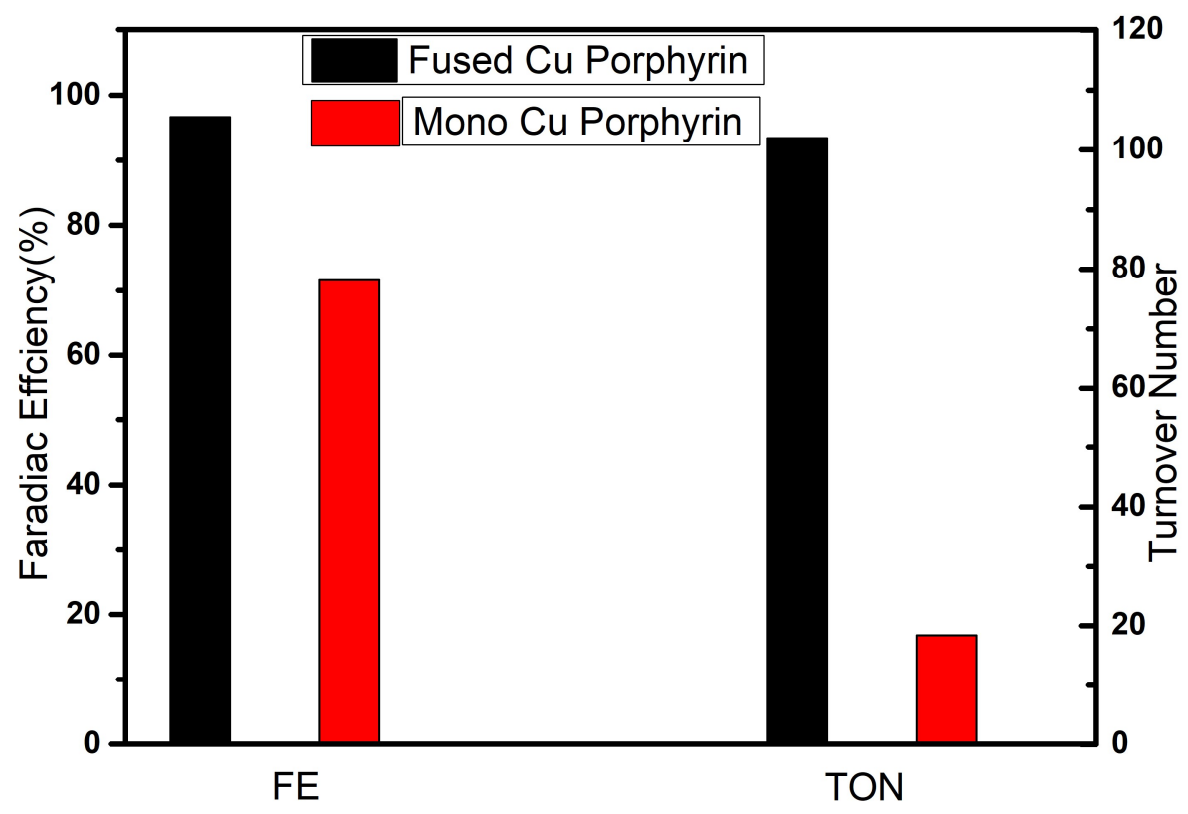

Figure 9. Comparison of Faradaic Efficiency and Turnover Number for $\mathbf{1}$ and 2.

To gain an insight into the mechanistic pathway of electrochemical HER with 1, one- and two-electron reduced species of the 1 were generated insitu (electrochemically) and through chemical reduction. Treatment of 1 with a stoichiometric amount of cobaltocene $\left(\mathrm{CoCp}_{2}\right)$ in $\mathrm{CH}_{2} \mathrm{Cl}_{2}$, resulted in the formation of light green colored one-electron reduced species $\mathbf{1}^{-}$, confirmed from the comparison of UV-Vis-NIR spectra of chemically (Figures S29 and S30) and insitu generated species (Figure 5). Addition of TFA to $\mathbf{1}^{-}$, leads to a new spectrum with simultaneous change in color of the solution from light green to yellow (Figure S30). Moreover, addition of large excess of TFA to this solution did not induce any significant spectral changes, implying lack of basicity of the one-electron reduced species to drive the protonolysis further (Figure S29). Thus, further reduction of $\mathbf{1}^{-}$is necessary to facilitate the catalytic process. To generate the doubly reduced species $\mathbf{1}^{2-}$, excess of $\mathrm{NaBH}_{4} / \mathrm{KC}_{8}$ was added into the DMF solution of 1 , resulting in immediate change in color of the solution from violet to deep green, indicating formation of the desired doubly reduced species as confirmed from the changes in the absorption spectra (Figure 10a). Similarity in the absorption spectrum of $1^{2-}$ generated either electrochemically or chemically, along with well-defined isobestic points confirms complete conversion of the ground state species to the doubly reduced form (Figure 10b). Importantly, treatment of the doubly reduced species with excess amount of TFA gave altered absorption spectra, which after some time slowly decayed back to 
regenerate the initial species 1, as confirmed from the identical UV-Vis-NIR spectrum of the reduced species containing TFA with that of the initial form (Figure 10c).

(a)
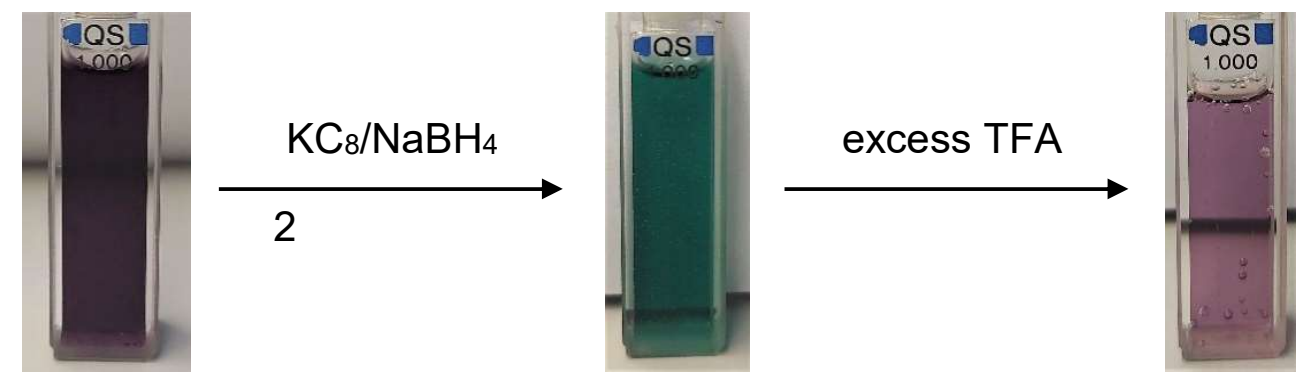

1

$1^{2-}$

$1^{2-+T F A}$

(b)

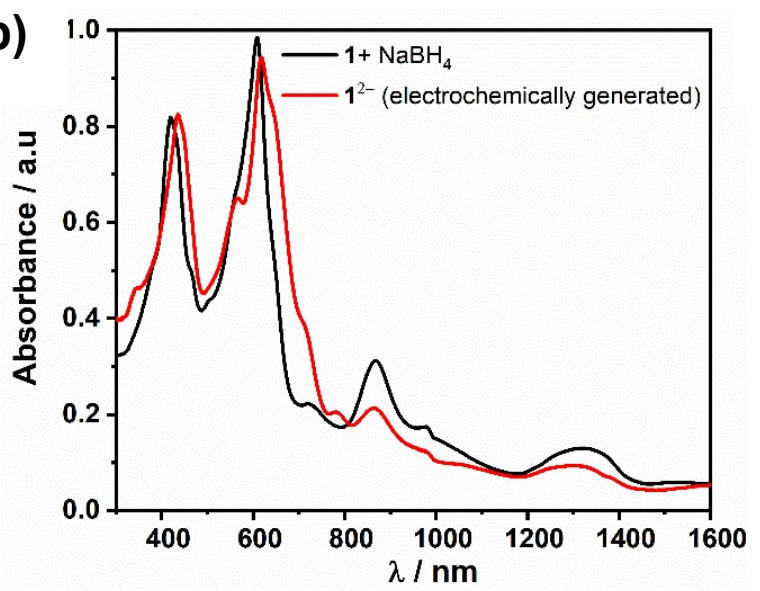

(c)

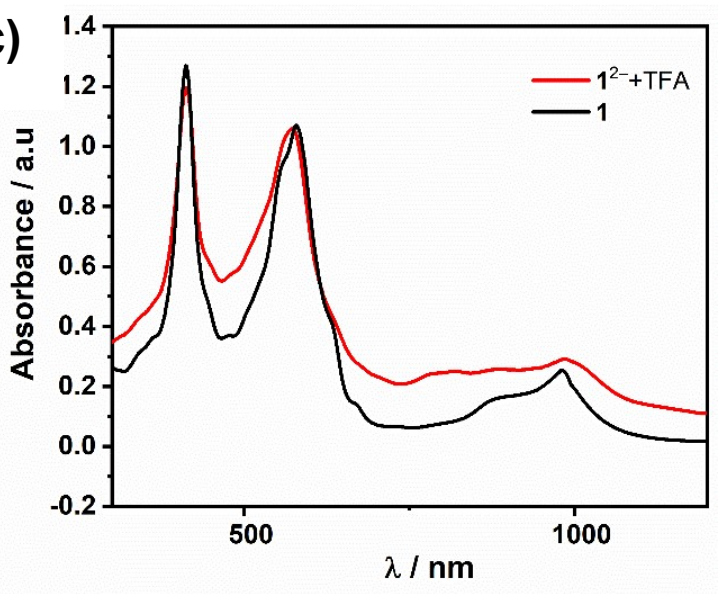

Figure 10. (a) Change in colour of the DMF solution of 1 upon two electron reduction (deep green) and reaction of the reduced species with TFA to regenerate the native species, (b)UV-Vis-NIR absorption spectra of the electrochemically (red) and chemically (black) generated doubly reduced species, and (c) Absorption spectra of the doubly reduced species with excess TFA (red) and native species 1 (black).

Conversion of the two electron reduced species to the initial species could also be followed from the noticeable change in color of the solution from deep green to violet (Figure 10a). EPR spectroscopic analyses of the one- and two-electron reduced species and their reaction with TFA led to the same conclusions, wherein doubly reduced species $1^{2-}$, generated via chemical reduction, on treatment with excess of TFA, reverts to the initial species 1 , as observed from the identical EPR spectra (Figure 11). Similarity in the absorption spectra obtained from electrochemical and chemical reduction emphasises identical redox behaviours of the transient species under chemical and electrochemical treatment. Thus, the aforementioned experimental 
observations strongly suggest possible involvement of the doubly reduced form, $\mathbf{1}^{2-}$ as a catalytically active species towards electrochemical reduction of protons to hydrogen.

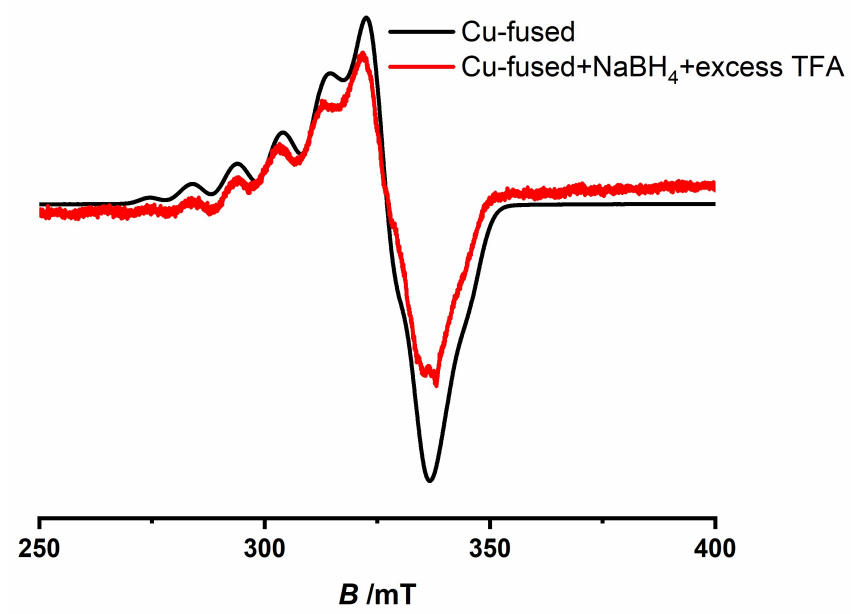

Figure 11. EPR spectra of the reaction of doubly reduced species $\left(1^{2-}\right)$ with excess TFA (red) and native species 1 (black).

Based on the information obtained from experimental analysis, we propose that the ground state species 1 undergoes two one-electron reductions to form doubly reduced species $\mathbf{1}^{2-}$, which subsequently reacts with protons generating a probable hydride intermediate. The intermediate species so formed, in presence of excess amount of TFA, reacts with a second proton to generate initial species along with the release of hydrogen. However, presence of two metals in the conjugated porphyrin system allows for a competitive scenario involving formation of a bimetallic hydride species. 


\section{Conclusion}

In summary, bimetallic copper complex (1) featuring a triply-fused porphyrin ligand was synthesized to generate a highly efficient molecular catalyst for electrocatalytic proton reduction. As indicated by cyclic voltammetric analysis, reduction processes in case of fused metalloporphyrin occured at lower applied bias potential, compared to the nonfused complex, with a difference of $\sim 800 \mathrm{mV}$ between the first reduction processes of each complex. Such a large margin of difference in reduction potentials is attributed to the extended delocalization of electrons within the fused porphyrin ligand, allowing easy tunability of the redox properties as compared to the well-known methods of using electron deficient functional groups to fine-tune the electrochemical potential in energy driven processes. Notably, 1 exhibited increased activity and lower onset potential towards proton reduction, compared to 2 . Consistent with the enhanced electrocatalytic activity, 1 significantly reduced the overpotential (by $\sim 320 \mathrm{mV}$ ), compared to 2 . These results taken together suggest positive impact of the fused scaffold over monomeric porphyrins on proton reduction, which is also reflected in significantly higher faradaic efficiency of the dinuclear complex ( $97 \%$ for 1 and $71 \%$ for 2). Further, the observed rate constant ( $k$ obs) of $1.9 \times 10^{7} \mathrm{~s}^{-1}$ is the highest reported rate constant so far among molecular electrocatalysts of the first row of transition metals for HER. Although, further analysis regarding identification of the mechanistic pathway as well as probable hydride intermediates is necessary, we managed to prove the involvement of the two-electron reduced species in electrochemical HER. To the best of our knowledge, this is the first time a metal complex (any metal) of a triply fused biporphyrin ligand has been used as a molecular electrocatalyst. Considering the excellent catalytic parameters obtained from the investigation (low over potential, stability of the molecular catalyst, high turnover numbers, unprecedented current densities and high rate constants), we expect metal complexes of triply fused biporphyrin ligands to play a very important role in energy related electrocatalytic work in the future. 


\section{Acknowledgements}

The high-performance computing facilities at ZEDAT of Freie Universität Berlin are acknowledged for access to computing resources. The core facility (BioSupraMol) is gratefully acknowledged. A.S.H kindly acknowledges funding from the European Union's Horizon 2020 research and innovation programme under the Marie Skłodowska-Curie grant agreement No. 894082. NIN is a member of CONICET. DFG SL104/10-1, SA1840/9-1. Landesgraduiertenförderung Baden-Württemberg are gratefully acknowledged. 


\section{References}

[1] a) T. R. Cook, D. K. Dogutan, S. Y. Reece, Y. Surendranath, T. S. Teets, D. G. Nocera, Chem. Rev. 2010, 110, 6474; b) H. B. Gray, Nat. Chem. 2009, 1, 7; c) D. G. Nocera, Acc. Chem. Res. 2012, 45, 767.

[2] a) Z. Han, F. Qiu, R. Eisenberg, P. L. Holland, T. D. Krauss, Science 2012, 338, 1321; b) A. Le Goff, V. Artero, B. Jousselme, P. D. Tran, N. Guillet, R. Métayé, A. Fihri, S. Palacin, M. Fontecave, Science 2009, 326, 1384.

[3] S. Dey, A. Rana, S. G. Dey, A. Dey, ACS Catal. 2013, 3, 429.

[4] M. L. Helm, M. P. Stewart, R. M. Bullock, M. R. DuBois, D. L. DuBois, Science 2011, 333, 863.

[5] J. L. Dempsey, B. S. Brunschwig, J. R. Winkler, H. B. Gray, Acc. Chem. Res. 2009, 42, 1995.

[6] I. Roger, M. A. Shipman, M. D. Symes, Nat. Rev. Chem. 2017, 1.

[7] a) S. Kaur-Ghumaan, L. Schwartz, R. Lomoth, M. Stein, S. Ott, Angew. Chem. Int. Ed. 2010, 49, 8033; b) M. J. Rose, H. B. Gray, J. R. Winkler, J. Am. Chem. Soc. 2012, 134, 8310.

[8] a) W. M. Singh, T. Baine, S. Kudo, S. Tian, X. A. N. Ma, H. Zhou, N. J. DeYonker, T. C. Pham, J. C. Bollinger, D. L. Baker et al., Angew. Chem. Int. Ed. 2012, 51, 5941; b) Y. Sun, J. P. Bigi, N. A. Piro, M. L. Tang, J. R. Long, C. J. Chang, J. Am. Chem. Soc. 2011, 133, 9212.

[9] a) H. I. Karunadasa, C. J. Chang, J. R. Long, Nature 2010, 464, 1329; b) H. I. Karunadasa, E. Montalvo, Y. Sun, M. Majda, J. R. Long, C. J. Chang, Science 2012, 335, 698.

[10] a) M. Kügler, J. Scholz, A. Kronz, I. Siewert, Dalton Trans. 2016, 45, 6974; b) X. Liu, S. Cui, Z. Sun, P. Du, Chem. Commun. 2015, 51, 12954.

[11] a) M. Gong, D.-Y. Wang, C.-C. Chen, B.-J. Hwang, H. Dai, Nano Res. 2016, 9 , 28; b) U. J. Kilgore, J. A. S. Roberts, D. H. Pool, A. M. Appel, M. P. Stewart, M. R. DuBois, W. G. Dougherty, W. S. Kassel, R. M. Bullock, D. L. DuBois, J. Am. Chem. Soc. 2011, 133, 5861.

[12] W. Lubitz, H. Ogata, O. Rüdiger, E. Reijerse, Chem. Rev. 2014, 114, 4081.

[13] H. S. Shafaat, O. Rüdiger, H. Ogata, W. Lubitz, Biochim. Biophys. Acta. 2013, $1827,986$.

[14] a) K. Hou, H. T. Poh, W. Y. Fan, Chem. Commun. 2014, 50, 6630; b) E. A. Mohamed, Z. N. Zahran, Y. Naruta, Chem. Commun. 2015, 51, 16900; c) D. 
Brazzolotto, M. Gennari, N. Queyriaux, T. R. Simmons, J. Pécaut, S. Demeshko, F. Meyer, M. Orio, V. Artero, C. Duboc, Nat. Chem. 2016, 8, 1054.

[15] J. Jökel, F. Schwer, M. von Delius, U.-P. Apfel, Chem. Commun. 2020, 56, 14179.

[16] a) W. M. Campbell, K. W. Jolley, P. Wagner, K. Wagner, P. J. Walsh, K. C. Gordon, L. Schmidt-Mende, M. K. Nazeeruddin, Q. Wang, M. Grätzel et al., J. Phys. Chem. C 2007, 111, 11760; b) J. S. Lindsey, D. F. Bocian, Acc. Chem. Res. 2011, 44, 638.

[17] a) B. B. Beyene, C.-H. Hung, Coord. Chem. Rev. 2020, 410, 213234; b) C.-M. Che, V. K.-Y. Lo, C.-Y. Zhou, J.-S. Huang, Chem. Soc. Rev. 2011, 40, 1950; c) W. Zhang, W. Lai, R. Cao, Chem. Rev. 2017, 117, 3717; d) C. Costentin, S. Drouet, M. Robert, J.-M. Savéant, Science 2012, 338, 90.

[18] I. Bhugun, D. Lexa, J.-M. Savéant, J. Am. Chem. Soc. 1996, 118, 3982.

[19] D. K. Bediako, B. H. Solis, D. K. Dogutan, M. M. Roubelakis, A. G. Maher, C. H. Lee, M. B. Chambers, S. Hammes-Schiffer, D. G. Nocera, Proc. Natl. Acad. Sci. U.S.A. 2014, 111, 15001.

[20] B. H. Solis, A. G. Maher, D. K. Dogutan, D. G. Nocera, S. Hammes-Schiffer, Proc. Natl. Acad. Sci. U.S.A. 2016, 113, 485.

[21] a) C. W. Li, J. Ciston, M. W. Kanan, Nature 2014, 508, 504; b) P. D. Tran, M. Nguyen, S. S. Pramana, A. Bhattacharjee, S. Y. Chiam, J. Fize, M. J. Field, V. Artero, L. H. Wong, J. Loo et al., Energy Environ. Sci. 2012, 5, 8912.

[22] a) H. Lei, H. Fang, Y. Han, W. Lai, X. Fu, R. Cao, ACS Catal. 2015, 5, 5145; b) K. Sudhakar, A. Mahammed, Q.-C. Chen, N. Fridman, B. Tumanskii, Z. Gross, ACS Appl. Energy Mater. 2020, 3, 2828.

[23] a) A. Tsuda, H. Furuta, A. Osuka, J. Am. Chem. Soc. 2001, 123, 10304; b) A. Tsuda, A. Osuka, Science 2001, 293, 79.

[24] D. Khusnutdinova, B. L. Wadsworth, M. Flores, A. M. Beiler, E. A. Reyes Cruz, Y. Zenkov, G. F. Moore, ACS Catal. 2018, 8, 9888.

[25] A. A. Ryan, M. O. Senge, Eur. J. Org. Chem. 2013, 2013, 3700.

[26] B. Bleaney, K. D. Bowers, Proc. R. Soc. Lond. A 1952, 214, 451.

[27] T. Ikeue, K. Furukawa, H. Hata, N. Aratani, H. Shinokubo, T. Kato, A. Osuka, Angew. Chem. Int. Ed. 2005, 44, 6899.

[28] M. Mares-Guia, E. Shaw, J. Biol. Chem. 1965, 240, 1579. 
[29] a) N. I. Neuman, E. Burna, R. Baggio, M. C. G. Passeggi, A. C. Rizzi, C. D. Brondino, Inorg. Chem. Front. 2015, 2, 837; b) A. Bencini, D. Gatteschi, Electron paramagnetic resonance of exchange coupled systems, Springer, Berlin, 1990.

[30] N. TOYAMA, M. ASANO-SOMEDA, Y. KAIZU, Mol. Phys. 2003, 101, 733.

[31] a) J. M. Assour, J. Chem. Phys. 1965, 43, 2477; b) Y. Hsu, Mol. Phys. 1971, 21 , 1087.

[32] V. Artero, J.-M. Saveant, Energy Environ. Sci. 2014, 7, 3808.

[33] a) R. H. Crabtree, Chem. Rev. 2012, 112, 1536; b) K. J. Lee, B. D. McCarthy, J. L. Dempsey, Chem. Soc. Rev. 2019, 48, 2927.

[34] J. G. Chen, C. W. Jones, S. Linic, V. R. Stamenkovic, ACS Catal. 2017, 7, 6392.

[35] a) C. Costentin, J.-M. Savéant, ChemElectroChem 2014, 1, 1226; b) K. J. Lee, N. Elgrishi, B. Kandemir, J. L. Dempsey, Nat. Rev. Chem. 2017, 1.

[36] U. J. Kilgore, J. A. S. Roberts, D. H. Pool, A. M. Appel, M. P. Stewart, M. R. DuBois, W. G. Dougherty, W. S. Kassel, R. M. Bullock, D. L. DuBois, J. Am. Chem. Soc. 2011, 133, 5861.

[37] P.-A. Jacques, V. Artero, J. Pécaut, M. Fontecave, Proc. Natl. Acad. Sci. U.S.A. 2009, 106, 20627.

[38] M. M. Roubelakis, D. K. Bediako, D. K. Dogutan, D. G. Nocera, Energy Environ. Sci. 2012, 5, 7737.

[39] Y. Han, H. Fang, H. Jing, H. Sun, H. Lei, W. Lai, R. Cao, Angew. Chem. Int. Ed. 2016, 55, 5457.

[40] M. van der Meer, E. Glais, I. Siewert, B. Sarkar, Angew. Chem. Int. Ed. 2015, $54,13792$. 